\title{
Infusing Multicultural Education into the Curriculum: Preparing Pre-Service Teachers to Address Homophobia in K-12 Schools
}

\author{
Joseph R. Jones \\ Mercer University \\ U. S. A.
}

\begin{abstract}
This article discusses the role multicultural education can play in addressing homophobia in K-12 schools. The author explores the lack of multiculturalism courses in undergraduate teacher education programs. To address the lack of multiculturalism courses, three instructional activities are offered that faculty in teacher education programs can implement as effective methods for preparing pre-service teachers to address homophobia.
\end{abstract}

KEYWORDS: homophobia, teacher education, curriculum, K-12 education, antiprejudice

Why My Course? It's Not the Diversity Course

A Personal Reflective Journey

A Non-Heteronormative School

Creating Supportive and Tolerant Classrooms

Implications

References

Over my academic career, I have worked with pre-service and in-service teachers who truly believe that homophobic bullying is a problem neither in their classrooms nor in their schools. Many of these individuals believe that the students in their buildings are "morally advanced" and would not project such hatred onto their classmates. In one undergraduate course, I brought homophobic bullying up as a topic to discuss. One student raised her hand and stated, "I don't think this is a problem in schools anymore. Like it was when you taught." Because of this experience, I began questioning my students' beliefs about homophobia in schools. My students were primarily upper middle class or upper class students, primarily White, and evenly divided between a male and female biological gender. All of the students had graduated high school within the past two years. I was surprised that approximately a third of the students did not believe homophobia was a problem in their schools. Many of those who did not believe it was a problem cited a shift in society's overall acceptance of same-sex marriage and came from one extremely affluent area in the state. 
For me, it was an undoubtedly an example of "straight privilege." By "straight privilege" I mean:

A set of benefits or presumptions that heterosexual individuals function within and often take for granted. For example, a heterosexual student can be almost certain that his or her classmates and teachers will be comfortable with his or her sexuality. Also, a heterosexual individual's sexuality is broadly displayed within the school's media, the curricula, and the yearbook, etc. (Jones, 2014, p. 20)

Additionally, heterosexual individuals are rarely harassed by others because of their self-identified sexual identity. Therefore, "straight privilege" causes the challenges of being non-heterosexual to become invisible to the heterosexual population. In this capacity, my students were blinded by the recent social changes toward gay, lesbian, bisexual, and transgender (GLBT) inclusion and believed homophobia no longer existed in schools. It is akin to believing racism no longer exists in the United States because we have an African American biracial president. Although my undergraduate students did not believe homophobic bullying is a problem in schools, the personal stories from nonheterosexual individuals and the national data argue differently and paint a different view of the culture of schools across the country.

The personal stories and national data depict the reality of homophobic bullying as an epidemic in our classroom and schools. Jones (2014) described the ordeal of Madison, a participant in his study:

His high school years were horrible. Although he had not come out in high school, everyone knew. They constantly harassed him, and he avoided sports because of the harassment and possible locker room assaults. He learned how to skip school without his parents finding out. However, his grades never suffered. He graduated with an incredibly high GPA. To him, high school was not about having fun, but rather it was about survival. ( $p$. 25)

There are significant numbers to corroborate Madison's high school experiences. The most recent survey by the Gay, Lesbian, Straight Education Network (GLSEN) (2011), which is the largest surveyor of national school climates, revealed that $71.3 \%$ of GLBT students heard homophobic language in their school and $56.9 \%$ heard homophobic slurs from their teachers. Further, $63.5 \%$ of GLBT students felt unsafe in their schools because of their sexual orientation, $81.9 \%$ of GLBT students were verbally harassed, and $38.9 \%$ were physically harassed. Of the GLBT students surveyed, $55.2 \%$ were cyber bullied. The study also revealed that GLBT students who are bullied are five times more likely to miss school because of homophobic bullying and $28 \%$ feel that dropping out of school is the only option available to remain safe. Moreover, the most alarming data revealed most homophobic bullying is not addressed by school officials.

As teacher educators we must reconceptualize how we instruct our preservice teachers and how their pedagogical practices are connected to 
eradicating the problem. Thus, as teacher educators, we must begin examining the role teacher education programs may play in addressing these challenges within our pre-service and in-service students' classrooms and schools. In order to address these problems, I hope to illuminate to all educators the importance of incorporating multicultural education in all teacher preparation programs and courses. To that end, I begin with a brief discussion of multicultural education, its connections with addressing homophobia, and its use in undergraduate teacher preparation programs. Afterward, I offer three practical instructional strategies in which to provide a commencement point to begin addressing homophobia in schools through teacher preparation programs.

\section{Why My Course? It's Not the Diversity Course}

For the purpose of this discussion, I borrow the broad definition of multicultural education as the process of creating acceptance of multiple cultures within educational settings. Multiculturalism dismantles the fear of rejection that may occur within educational settings as it relates to cultural difference (Jones, 2014). In this manner, "multiculturalism in education is the quality of creating and sustaining curricula, academic activities, programs, and projects that actively enhance respect for all human cultures" (Asante, 1996, p.21). Further, Nieto (1992) argued that multiculturalism "challenges and rejects racism and other forms of discrimination in schools and society and accepts and affirms the pluralism (ethnic, racial, linguistic, religious, economic and gender among others) that students, their communities, and teachers represent" (p. 208).

Utilizing this definition, I postulate that multiculturalism can be the conduit to eradicate homophobic bullying within classrooms and schools by creating classrooms that value all cultures. As such, multiculturalism raises awareness of gay, lesbian, bisexual and transgender (GLBT) culture. GLBT culture is a shared set of beliefs and acknowledgments among the gay, lesbian, bisexual and transgender community. It is a culture that maintains a history of oppression and hatred, civil rights, and community activism. According to Nowlan (2008), queer culture can be traced throughout recent history including events such as the Stonewall Riots, the AIDS epidemic, and the modern gay rights movement. In addition to the historical aspect of culture, Nowlan (2008) argues that GLBT individuals live and function within a community that has established a distinct culture through contributions to literature, art, film, history, and language. It is a culture that maintains a set of practices and belief systems that one must navigate in order to function within GLBT community. Such practices can be as simple as understanding that some gay men who are in committed relationships may choose to wear wedding bands on their right hand, instead of the left hand (Jones, 2014).

Beyond acknowledging the GLBT culture, Letts (2002) suggests using multiculturalism as a conduit to teach pre-service teachers how sexual diversity helps to make visible the lives of gay and lesbian students. In this capacity, 
teachers learn about sexual differences in the same manner through which they learn to address differences in race, class, and gender. Other scholars also believe that multiculturalism is key in constructing tolerant classrooms for GLBT students, and in order for gay and lesbian students' culture to be validated by schools, teachers need to learn appropriate ways to integrate GLBT culture into their classrooms, which can be done through multicultural education. Further, multicultural education can destroy the oppressive nature of binaries such as self and other, gay and straight. In doing so, teachers must work against the oppression that exists within society and schools. As such, multiculturalism is a catalyst through which educators can begin to address GLBT culture within schools and classrooms.

However, there are challenges that surround using multicultural education and its effectiveness in combating this problem. According to Gibson (2004), "The lack of meaningful multicultural preparation and the fact that most teachers come from isolated ethnic groups, and possess professional preparation that usually excludes direct meaningful interaction with different cultures create problems for proper multicultural understanding" (p. 2). In fact, few teacher preparation programs have a course solely devoted to multicultural education within their undergraduate teacher education program (Chou, 2007; Gibson, 2004; Jones, 2014; Kea, Campbell-Whatley, \& Richards, 2006). Rather, undergraduate programs have a mention of diversity sparsely spread throughout their program and coursework (Gibson, 2004; Kea, Campbell-Whatley, \& Richards, 2006). This is problematic because the discussions surrounding cultural diversity rest solely on the professor teaching the courses and his or her syllabus, which may change drastically as the professor teaching the course changes. There is not a formalized set of standards embracing multicultural education. As such, Bodur's (2003) recommendations to more fully integrate social justice topics into the curriculum are still something that needs to be accomplished.

Because most undergraduate programs are inundated with their own curricular challenges, the current condition of multicultural education in undergraduate teacher education programs will not change drastically in the near future. Further, because a number of practicing teachers have no plans to attend graduate programs, it is unlikely that those teachers will receive formal training in implementing multiculturalism in their classrooms. Nevertheless, pre-service and in-service teachers need concrete instructional strategies in order to address homophobic bullying. For many years, teacher preparation programs have simply discussed the theoretical underpinnings of multicultural education when possible, leaving teachers few concrete strategies to implement as part of their pedagogy. There are few practicing classroom teachers who are aware of the role multicultural education can play in addressing homophobia in their schools. Further, as teacher educators, we must move beyond our current instructional methods and provide pre-service teachers with practical activities that can be utilized within their classrooms in order to create the necessary change. 
Teacher candidates' level of tolerance towards difference rises after learning about different cultures, which may help to reduce intolerance in educational environments. Therefore, as Nieto and Bode (2011) postulate, educators and school leaders must combat all intolerance so that our students can grow into more tolerant and accepting citizens. To that end, we must train our pre-service teachers how to address all intolerance, including intolerance towards GLBT students.

Thus, I posit that the role of multicultural education is paramount in eradicating homophobia in schools. I believe multicultural education and curriculum must be added to all current course objectives where feasible. As teacher educators, we must help our pre-service teachers conceptualize how multicultural education can influence the level of tolerance in their school buildings. GLBT culture must be incorporated into the current pedagogical practices. For these reasons, I offer three activities that I have conducted with our undergraduate and graduate students to help them address homophobic bullying in classrooms and schools.

\section{A Personal Reflective Journey}

Reflective journeys are not new to teacher education, and they involve a level of self-searching and self-discovery that can impact practice (Maarof, 2007). In fact, Fiedler, Chiang, Van Haren, Jorgensen, Halberg, and Boreson (2008) argue that addressing issues of diversity must involve reflections of personal assumptions about difference. Further, other scholars postulate teachers must examine how their own deeply held beliefs impact how they view difference (Kendall, 1996). Jacobsen (2003) and Ramsey (2004) similarly posit that teachers must recognize and analyze their own reactions to diversity. All of these scholars believe that reflective analysis can create a more tolerant classroom atmosphere.

In order to truly eradicate homophobic bullying in schools, our teacher education programs must provide opportunities for our students to engage in personal reflective journeys that become a conduit for reflection on the influences of homophobia. As mentioned above, a number of my undergraduate teacher candidates did not believe that homophobia was still prevalent in schools. To many of them, the small societal shift toward same-sex marriage was an indicator of a more tolerant society which impacts local schools. Despite the national data indicating the dire reality of the impact of homophobia in education settings, not only did a number of my undergraduate students not believe it is a problem, but this disbelief also exists among practicing teachers and school administrators. A gay interviewee in Jones' (2010) study stated, "I really don't think this is that important to others as it is to me. Until it happens in their schools, someone getting shot, things will not change. There is still such a stigma attached to being gay. And how do you change that?" (p. 2). I argue the process of change involves a personal journey. 
In discussing his personal journey, a high school social studies teacher wrote the following email:

I have been teaching high school social studies for 15 years. I am an assistant football coach. I am Southern Baptist and was taught homosexuality was wrong. I have three kids. One of my kids in middle school came home and told me that he was being picked on. The kids were calling him queer and other stuff. Being a high school teacher, I never really thought about this a lot. I teach in small town America. Being picked on is part of growing up. But, then I saw CNN and a kid killed himself because of this. I started thinking about what if it was my kid. I Googled some stuff and found your site. I watched the videos. It changed the way I think about this stuff. I want to say that it changed the way that I conduct class. I am purposefully paying more attention to it in my classroom and school. Do I still believe that homosexuality is wrong? Probably. But, all kids should feel safe in school. Kids are there 8 sometimes more hours a day. It is a long time to be miserable every day. (Jones, 2014, p. 80)

For this teacher, homophobic bullying was not something he recognized or attempted to address in his school and classroom, partly because of his personal beliefs about non-heterosexuality. The correspondence suggests the teacher engaged in a personal journey that involved a metacognitive process. It was a personal exploration that involved his own child and his child's experiences in middle school.

Because of this lack of awareness and intervention, I argue all pre-service teachers must be made aware of this devastating problem in our schools. Thus, this first activity asks students to engage in a cultural awareness project. In groups of four, students are required to research two cultures, the GLBT culture and one other of their choice. In their research, students are required to do the following: (a) trace each culture's historical development in Western society; (b) discuss how the media have traditionally represented the culture in Western society; (c) discuss any stereotypes about the culture; (d) discuss how the culture is represented with the schools; and (e) write a reflective analysis of how their research will impact their future classroom practice.

This activity causes students to engage deeply with two cultures to which they may or may not belong. Students are required to examine how society has marginalized the cultures and how such marginalization has impacted the individuals within the culture, especially within the process of schooling. Finally, the activity requires students to connect their new knowledge surrounding the two cultures to their future classroom pedagogy.

This activity positively impacted my students' beliefs about individuals who are marginalized. In an informal interview, many of my students made statements such as, "I had never considered how the group was treated in our society. I am going to make sure it does not happen in my classroom." In specifically addressing non-heterosexual students in schools, one of my students wrote in 
her reflective analysis, "I will never allow any student to say 'that's so gay' in my classroom because it can be offensive to another student; no matter how the word was meant to be used." Another student wrote, "I have gay friends, and I never realized how my actions could be perceived as homophobic by them and others."

Personal awareness is a vitally important part in combatting homophobia within schools. I argue educators must realize the extent to which homophobic bullying exists within schools, and this activity elucidates the problem to our preservice students. In doing so, it is the first step in preparing our teacher candidates to address the challenge in their future classrooms and schools.

\section{A Non-Heteronormative School}

One of the tenets of multicultural education is to recognize the intersections between minorities and the schooling process. As such, one aim of multiculturalism is to reject all forms of prejudice and discrimination through recognizing and affirming diversity such as racial and linguistic differences (Nieto, 1992). Further, other scholars posit that multiculturalism becomes a way to discuss racial and socioeconomic privilege in society and schools (Aveling, 2006; Lipman, 1996; Moss, 2008). In this manner, multiculturalism can be used to critically examine the systems of power that control our views of race and ethnicity. I argue that multicultural education can also be used to address the power system that controls our understandings of sexuality.

Heteronormativity is a powerful force within society and by extension educational settings. It controls the treatment of all community members. Within schools, it controls curriculum and decision-making processes. In some cases, it controls the hiring of faculty and staff. Heteronormativity is the process of privileging a heterosexual identity over all other identities by claiming heterosexuality is normal and acceptable and all other identities are antithetical. In this capacity, heteronormativity only exists because of the notions of hegemony. For the sake of brevity, I borrow a broad definition of hegemony as the process of those who are dominant in society controlling the others in society who are less powerful than the dominant group. In this manner, the ones who hold the power in our society have dictated that heterosexuality is the normal and acceptable identity for our society. Because of hegemony, other sexual identities are rejected, thus allowing heteronormativity to thrive.

In recognizing the challenges of homophobia in educational settings, I postulate that educators must recognize the existence of not only heteronormativity but also its connections to "straight privilege" and its functions within educational settings. As discussed above, "straight privilege" is a real challenge within society and by extension within schools. Although persons with heterosexual identities will never be capable of fully understanding how "straight privilege" impacts the lives of non-heterosexual identities, it is necessary for 
heterosexual individuals to recognize and examine how it functions with schools and how it impacts the culture of their classrooms.

Thus, we must begin preparing our pre-service teachers with instructional strategies to recognize heteronormativity and "straight privilege" within their classrooms and schools. To that end, I offer one activity that I have conducted with a class in an undergraduate teacher preparation program to help them recognize and potentially influence and create fewer heteronormative classrooms.

First, I placed the students into groups and gave them a copy of ESPN's Body Issue. However, any mainstream magazine will be appropriate for this activity. The Body Issue is an annual publication of a collection of mostly nude athletes; nothing provocative is revealed. After passing the copy to each group, I allow the students 15 minutes to review the publication, with instructions to only view the photographs. When the time has ended, I instruct them to view the publication again answering the following question: What thoughts immediately come to mind when you view these photographs? After an appropriate amount of time, students are given the next question: What does this publication teach you about gender and about sexuality? In essence, the students are deconstructing the media, revealing its "true" message.

When we complete our class discussion concerning the Body Issue and its role in perpetuating stereotypes about gender and sexuality, we transition into the same activity with Disney movies. I give the students titles of Disney movies that my US-based students may have viewed, and I follow the steps above substituting the films for the photographs. I end the activity discussing how Disney movies continue to perpetuate gender and sexuality roles and how heteronormativity is supported throughout the films.

After completing the first two assignments, students are required to use the same process modeled in class to analyze their content area curriculum. Thus, a pre-service student majoring in secondary English education would examine a high school English/ELA curriculum. Students are given specific guiding questions such as the following:

- What underlying messages are embedded in the texts used in the curriculum?

- What stereotypes are perpetuated through the texts used in the curriculum?

- What does the curriculum teach students outside of academic content?

- What are some possible replacement texts that could be used instead?

In essence, the students will discover the hidden curriculum of their texts.

In one student's submission, he discussed how literature written by women authors was only confined to a specific type of writer. He stated, "We are only reading Plath, Woolf, and Gillman, among others. Where are the powerful woman writers?" He continues: "Only teaching women writers who suffered 
sends a message to our female students about what a successful woman writer is." He suggests English teachers add texts by successful women authors to balance out the view. Another student made the connection with African American and women scientists. The lack of discussions concerning the contributions from these minorities to science paints an erroneous picture for our students to view. In addressing gender and GLBT students, one pre-service teacher wrote, "There is no literature discussing gay and lesbian issues in the English curriculum. We teach gay and lesbian students, yet they are not represented like other students; we are silently invalidating their lives."

As Jackson (2013) notes, there are moments in the K-12 curriculum to naturally discuss non-heterosexual identities. However, many of our pre-service educators need to conceptualize the true impact of heteronormativity before they can begin using those natural spaces in the daily process of schooling. The curriculum analysis is a powerful activity that causes students to examine their future curriculum through a lens that they may have never considered. In doing so, it causes them to realize the power of heteronormativity in the daily process of schooling, and hopefully removes some of the "straight privilege" that exists within their classrooms.

\section{Creating Supportive and Tolerant Classrooms}

The final activity I have used with our pre-service teacher candidates to help address homophobic bullying involves creating a model classroom that is supportive and tolerant of all cultures and differences. In this activity, my students are required to design their future classrooms around the physical attributes and emotional attributes that create supportive and tolerant classrooms. Physical attributes involve desk and all furniture placement and classroom décor. Students are required to ground their beliefs around a theoretical perspective to justify their room's physical design elements. For example, a student who believes in constructivism would design his or her classroom in a very different manner from a non-constructivist teacher. Students also must locate any photographs of posters and wall décor that they wish to display in their rooms. These choices must also be defended by the teacher candidate. Further, students are required to design a list of rules and consequences for their classrooms. These rules and consequences should foster the creation of a supportive and tolerant classroom. In the past, students have used "tolerant" in their rule list.

This activity is important because it teaches my pre-service teachers not only how to design a classroom, but also how to allow one's philosophy of tolerance to guide every classroom decision. It is important because it forces students to explore cognitively why the physical placement of desks, chairs, and tables is so vitally important. Students realize the importance of using posters that represent more than the White maleness that exists within society. The walls become a space used to promote the value of diversity among all cultures, such 
as the African American poet, the female physicist, or the non-heterosexual mathematician. In essence, the walls become a pictorial representation of the teacher's beliefs about diversity and acceptance, which his or her students will recognize. Thus, our students recognize the importance of making all students feel welcomed and supportive.

In addition to the physical space, students must explore the necessary beliefs about classroom management. For example, should teachers allow students to help in writing the rules and consequences? Should students write all the rules and consequences? Does this process promote a supportive tolerant classroom? Further, my students are required to examine what rules are truly necessary and what are the most appropriate consequences. During this activity, students begin to conceptualize how important it is to address unwanted language and how such language should be addressed. For example, should there be a rule about using hate language of any type? If so, what should the consequence be for using such hate language?

After each assignment, I always require students to write an anonymous reflection about the assignment and their learning process. For this assignment, many students wrote comments about their realization of how their philosophical beliefs impact every decision in the classroom. One student wrote, "My beliefs about race, gender, and sexuality dictate how I decorate my room. If I value difference and want my students to feel safe, I have to have different posters of people on my walls. This assignment caused me to realize how it all intersects." Another student wrote, "If an African American student came into my room and only saw white people on the wall, would he feel safe in my room? What about a gay student?...This assignment made me realize that every decision I make in my classroom will impact how safe my students feel."

For my students, this assignment engendered metacognitive choices concerning how classrooms represent an atmosphere of acceptance and tolerance. In many ways, the assignment was the catalyst that caused the students to consciously create classrooms that embrace all types of difference, including non-heterosexual identities.

\section{Implications}

As the data above depict, homophobic bullying is a tremendous problem in our schools. However, one of the most alarming statistics indicates that a number of faculty members do not intervene to stop the bullying behaviors. This raises several questions: Are faculty members aware that the bullying is taking place? Are faculty members trained to address it appropriately? Are faculty members tolerant of GLBT students in their own schools?

Addressing these questions and many others is important and can be done through appropriate multicultural education coursework. However, as discussed, multiculturalism is sparsely spread throughout the undergraduate 
teacher preparation program. Thus, teacher educators must begin contemplating new avenues to address homophobia within the constructs of the current undergraduate teacher education program. I offer these three pedagogical practices that can be implemented into most undergraduate teaching coursework to raise awareness concerning homophobic bullying.

My hope is to provide faculty in teacher education programs tools to begin preparing pre-service students to address homophobia and homophobic bullying within schools and classrooms. As the data reveal, the necessity of creating safe schools for GLBT students is great. GLBT students should not have to wait for teacher education programs to restructure curriculum to include an undergraduate multiculturalism class that includes discussions of nonheterosexual identities. Instead of merely waiting, the faculty in teacher education programs without a formalized multiculturalism course should begin infusing multiculturalism whenever the course curriculum provides such an opportunity. I have provided three activities that can be utilized for this purpose within a number of traditional undergraduate teacher preparation courses. These activities provide a commencement point to begin discussions concerning the challenges GLBT students face in schools. I posit that K-12 GLBT students will benefit from pre-service teachers engaging in a reflective journey, understanding heteronormativity, and creating a supporting classroom. Our K-12 students deserve a safe and tolerant school in which to learn, to grow, and to become the best adults possible.

\section{References}

Asante, M. (1996). Multiculturalism and the academy. Academe, 82(3), 20-23.

Aveling, N. (2006). Hacking at our very roots: Rearticulating white and racial identity within the context of teacher education. Race, Ethnicity and Education, 9(3), 261-274.

Bodur, Y. (2003). Preservice teachers' learning of multiculturalism in a teacher education program. Electronic Theses, Treatise and Dissertations. Florida State University.

Chou, H. (2007). Multicultural teacher education: Toward a culturally responsive pedagogy. Essays in Education, 21(4) 139-162.

Fiedler, C. Chiang, B., Van Haren, B., Jorgensen, J., Halberg, S., \& Boreson, L. (2008). Culturally responsive practices in schools: A checklist to address disproportionality in special education. Teaching Exceptional Children, 40(5), 52-59.

Gibson, C. (2004). Multicultural pre-service education: Promising multicultural pre-service teacher education initiatives. Radical Pedagogy 6(1). Retrieved from http://radicalpedagogy.icaap.org/content/issue6 1/ gibson.html 
GLSEN (2011). Retrieved from www.glsen.org

Jackson, J. (2013). How do you spell homosexual?: Naturally queer moments in K-12 classrooms. In Soler, J., Walsh, C., Craft, A., Rix, J., \& Simmons, K. (Eds.). Transforming practice: Critical issues in equity, diversity and education (pp. 81-99). London, UK: Open University Press.

Jacobsen, T. (2003). Confronting our discomfort: Clearing the way for anti-bias in early student-hood. Portsmouth, NH: Heinemann.

Jones, J. (2010). Making safe places unsafe: A discussion of homophobia with teachers. Dubuque, IA: Kendall Hunt.

Jones, J. (2014). Unnormalizing education: Addressing homophobia in higher education and K-12 Schools. Charlotte, NC: IAP.

Kendall, F. (1996). Diversity in the classroom: New approaches to the education of young children. New York, NY: Teachers College.

Letts, W. (2002). Revisioning multiculturalism in teacher education: Isn't it queer? In R. Kissen (Ed.). Getting ready for Benjamin: Preparing teachers for sexual diversity in the classroom (pp. 119-131). New York, NY: Rowman \& Littlefield.

Lipman, P. (1996). The missing voice of culturally relevant teachers in school restructuring. The Urban Review, 28(1), 41-62.

Maarof, N. (2007). Telling his or her story through reflective journals. International Education Journal, 8(1), 205-220.

Moss, G. (2008). Diversity and study circles in teacher education practice: An experiential learning process. Teaching and Teacher Education, 24(1), 216-224.

Nieto, S. (1992). Affirming diversity: The sociopolitical context of multicultural education. Mahwah, NJ: Erlbaum.

Nieto, S., \& Bode, P. (2011). Affirming diversity: The sociopolitical context of multicultural education ( $6^{\text {th }}$ ed.). Boston, MA: Pearson.

Nowlan, B. (2008). Lectures: Introduction to critical theory and gender. Retrieved from http://www.uwec.edu/ranowlan/theory_teaching

Ramsey, P. (2004). Teaching and learning in a diverse world. New York, NY: Teachers College.

\section{Author Contact}

Joseph R. Jones: jones_jr@mercer.edu

Assistant Professor, Tift College of Education, Mercer University, 1501 Mercer University Drive, Macon, GA 31207, USA 
Vol. 17, No. 3 